\title{
BMJ Open Cumulative exposure to ionising radiation from diagnostic imaging tests: a 12-year follow-up population-based analysis in Spain
}

Blanca Lumbreras, ${ }^{\oplus 1,2}$ Josee María Salinas, ${ }^{3}$ Isabel Gonzalez-Alvarez ${ }^{4}$

To cite: Lumbreras B, Salinas JM, Gonzalez-Alvarez I. Cumulative exposure to ionising radiation from diagnostic imaging tests: a 12-year follow-up population-based analysis in Spain. BMJ Open 2019;9:e030905. doi:10.1136/ bmjopen-2019-030905

- Prepublication history and additional material for this paper are available online. To view these files, please visit the journal online (http://dx.doi. org/10.1136/bmjopen-2019030905).

Received 05 April 2019 Revised 22 July 2019 Accepted 26 July 2019

\section{Check for updates}

C Author(s) (or their employer(s)) 2019. Re-use permitted under CC BY-NC. No commercial re-use. See rights and permissions. Published by BMJ.

${ }^{1}$ Department of Public Health, Miguel Hernandez University of Elche, Alicante, Spain

${ }^{2}$ CIBER en Epidemiología y Salud Pública, Alicante, Spain ${ }^{3}$ Information Technology Department, San Juan Hospital, Alicante, Spain

${ }^{4}$ Radiodiagnostic Department, San Juan Hospital, Alicante, Spain

Correspondence to Dr Blanca Lumbreras; blumbreras@goumh.umh.es

\section{ABSTRACT}

Objectives To calculate each patient's cumulative radiation exposure and the recurrent tests during a 12year study period, according to sex and age, in routine practice.

Design Retrospective cohort study.

Setting A general hospital with a catchment population of 224751 people, in the Southeast of Spain.

Participants Population belonged to the catchment area of that hospital in 2007. We collected all consecutive diagnostic imaging tests undergone by this population until 31 December 2018. We excluded: imaging tests that did not involve radiation exposure.

Main outcome measures The cumulative effective dose and the recurrent imaging tests by sex and age at entry of study.

Results Of the 224751 people, 154520 (68.8\%) underwent an imaging test. The population had 1335 752 imaging tests during the period of study: 1110 077 (83.0\%) plain radiography; 156848 (11.8\%) CT; 63 $157(4.8 \%)$ fluoroscopy and $5670(0.4 \%)$ interventional radiography. $25.4 \%$ of the patients who had a $\mathrm{CT}$, underwent five or more CTs $(5.4 \%$ in the $0-20$ years age group). The median total cumulative effective dose was $2.10 \mathrm{mSv}$ (maximum 3980.30) and $16.30 \mathrm{mSv}$ (maximum $1419.30 \mathrm{mSv}$ ) if we considered only doses associated with CT. Women received more effective dose than men (median 2.38 vs median $1.90, p<0.001$ ). A total of 7142 (4.6\%) patients received more than $50 \mathrm{mSv}$, with differences in men and women $(p<0.001)$ and $2.5 \%$ of the patients in the $0-20$ years age group, if we considered only doses associated with CT.

Conclusions Nearly $5 \%$ of patients received doses higher than $50 \mathrm{mSv}$ during the 12-year period of study and $2.5 \%$ of the patients in the $0-20$ years age group, if we considered only doses associated with CT. The rate of recurrent examinations was high, especially in older patients, but also relevant in the $0-20$ years age group.

\section{INTRODUCTION}

The use of ionising radiation in medicine provides valuable diagnostic information that undoubtedly benefits many patients. However, this radiation is also the greatest source of artificial radiation exposure. ${ }^{1}$

\section{Strengths and limitations of this study}

- This study follows the Basic Safety Standards Directive adopted by the European Union in 2013 in order to assess the amount of effective dose that patients receive during their lifetime.

- The analysis of medical records allowed us to evaluate all imaging tests performed in a cohort of 224 751 patients in routine practice during a 12-year study period, according to sex and age.

- The retrospective design did not allow a detailed assessment of the longitudinal nature of the exposure.

- Instead of recording the effective dose for each individual examination, we used the available evidence, as is proposed by the Dose DataMed project.

- The inclusion of a general hospital and its catchment area could have led to some limited generalisability in other settings.

In the last decades, there has been an increase in utilisation of X-rays, particularly of CT. Although a single CT scan does not present a significant risk for patients' health, each additional scan increases the potential for cancer-inducing biological damage ${ }^{2}$ and patients may receive multiple CT scans over time. $^{3}$

According to stochastic effect theory and based on the estimated incidence of fatal cancer from the International Commission of Radiation Protection (ICRP), as well as from the Biological Effects of Ionising Radiation Committee VII (BEIR VII), an effective dose of $100 \mathrm{mSv}$ results in a risk of fatal cancer of approximately 1 in 200 in adults, and 1 in 100 for combined fatal and non-fatal cancer. ${ }^{4}$ Moreover, although the BEIR VII report concludes that at doses lower than 100 $\mathrm{mSv}$, the risk of cancer is small, ${ }^{5}$ the Radiation Effect Research Foundation (RERF) in Japan, defends a 'linear-no-threshold' risk model, where the risk of cancer follows in a linear fashion at lower doses, without a threshold. 
Smaller doses, therefore, have the potential to cause a small increase in cancer risk. ${ }^{6}$

A recent study in France ${ }^{7}$ estimated that $0.7 \%$ of all new cancer cases in 2015 were attributable to medical ionising radiation. In Spain, a rate of 10.9 scans per 1000 children and young adults ( $0-20$ years) was estimated in 2013, and a total of 168.6 cancer cases (95\% CI 30.1 to 421.1 ) will be attributable to these CTs. ${ }^{8}$

Concern regarding the effects of ionising radiation from these medical tests on population health and the estimated increased risk of cancer for the population in general, and for children and young adults in particular $(0-20 \text { years })^{910}$ has led to several initiatives to reduce the use of ionising radiation.

The Basic Safety Standards Directive was adopted by the European Union (EU) in $2013^{11}$ to be transposed into national law by 6 February 2018. One key and innovative surveillance mechanism in this revised directive is to record the radiation dose received by each patient undergoing a medical imaging test. The directive mainly focuses on CT and tests involving interventional radiology, all of which are associated with a relatively high dose of radiation. Other diagnostic tests such as conventional radiography, however, are also frequently repeated in patients during their lives with a potential impact on health and could be included in these evaluations. However, these evaluations have not still been developed in the European countries as a systematically procedure.

A full evaluation of the radiation exposure from all medical diagnostic tests in Europe has been previously carried out in the project Dose DataMed I and II. ${ }^{12}{ }^{13}$ This project, based on national surveys, includes information on 36 European countries regarding population frequencies and radiation dose of X-ray and nuclear medicine radiodiagnostic tests. Although this project has led to a significant advance in the evaluation of population doses, we still do not have data regarding the cumulative dose in routine practice received by patients during long time periods. Some previous studies carried out in routine practice have evaluated the cumulative effective dose by focusing on specific pathologies, ${ }^{14}$ population groups ${ }^{15}$ or the effect of recurrent CT. ${ }^{3}$ The previously mentioned study in France $^{7}$ assessed the cumulative exposure in adults of 30 years of age and older, using 2007 national frequencies of imaging tests and adjusted for changes in the use of these tests over time. However, none of them have evaluated the cumulative radiation exposure derived from all diagnostic tests carried out in routine practice during a long period of time, for both adults and children.

Given that the number of people who have these examinations many times during their lifetime has increased, ${ }^{3}$ the detection of patients with high cumulative radiation derived from recurrent imaging tests will help clinicians to reduce patient-specific-associated cancer risks. Moreover, the identification of the clinical context of patients with high cumulative radiation doses due to repeat imaging could help clinicians to reduce the use of ionising radiation. ${ }^{16}$ According to previous literature, patients with a diagnosis of neoplasm are prone to have recurrent imaging tests. ${ }^{3}$

The purpose of this study was to quantify the number of all radiological investigations performed in a cohort of patients in routine practice to calculate each patient's cumulative radiation exposure and the recurrent tests during a 12-year study period, according to sex, age, focusing on children and young adults (0-20 years) and imaging test. In addition, we identified the clinical context of patients with potentially high cumulative radiation risks.

\section{METHODS}

\section{Study design}

We conducted a retrospective cohort study to analyse the individual cumulative effective dose in routine practice and the recurrent imaging diagnostic tests.

\section{Setting}

The target population for the study were all residents in the catchment area of San Juan Hospital (Alicante), in the Valencian Community (Spain), a general centre, with a catchment population of 234424 people. This is a referral hospital for all individuals living in the catchment area who belong to the National Health Care System (NHS). The majority of the Spanish population uses the NHS as the main medical service (the publicly funded insurance scheme covers $98.5 \%$ of the Spanish population) and hence, only a small percentage of patients are likely to have had imaging tests outside this setting.

\section{Participants}

We selected the population who belonged to the catchment area of that hospital during the year 2007, and collected all consecutive diagnostic imaging tests undergone by this population until 31 December 2018 (in any care setting, inpatient, outpatient or emergency department). Cohort members remained in the study until their exit date or they left the catchment area. We assigned each person to the unexposed group from the date of entry until the date of the first imaging test, and to the exposed group from the date of the first imaging test until the exit date. In addition, in those patients who did not account for the 12 years of follow-up, we assumed future practice estimating the proportion of imaging tests that would have been carried out during the remaining period if the patients had been in the cohort, except for the $>80$ years age group, where did not implemented this strategy given that the expectancy life in Spain is 82.83 years old.

We excluded: imaging tests that did not involve radiation exposure (ie, MRI and ultrasound) and patients who had an imaging test in this hospital but did not belong to its catchment area.

We classified the population in different age groups, and we focused our estimations in the $0-20$ years old group due to their increased cancer risk. 
In order to check generalisability of our data, we compare our population with Spanish population on the 31 December 2007. ${ }^{17}$

\section{Imaging test frequency}

We collected the following data from Medical Image Bank of the Valencian Community from the Department of Universal Health and Public Health Service: sex and age at entry in the study, radiological examination and date. Both the images and the patient data were anonymised and deidentified by the Health Informatics Department of the Hospital of San Juan using Research and Development (R\&D) Cloud CEIB Architecture ${ }^{7}$ This digital register started in 2007 in our setting.

According to previous studies, ${ }^{3}$ each imaging test received was classified as a single radiation exposure. However, abdomen and pelvis tests carried out in the same process were included as a single abdomen-pelvis test, while an abdomen or pelvis test in a different process, even in the same patient, were included as two different tests. Thoracic and lumbar spine tests were included when they were performed alone but not when performed together with chest or abdominal tests.

\section{Effective dose estimate}

Given that it was impossible to get individual machine parameters for all imaging tests, we estimated the associated radiation effective dose per test according to its region of anatomical coverage by age and using previously published evidence ${ }^{18}$ This review provides values of the typical effective doses associated with the 20 most frequent imaging tests for adults and children and for the most widely used set of weights (ICRP60) as well as for the most recent (ICRP103). We based our estimates on ICRP103, except in those cases where we did not have enough information. In addition, we estimated the effective dose of imaging tests different from the 20 most frequent imaging tests in Dose DataMed 2 project according to previous bibliography ${ }^{19-21}$ (online supplementary tables 1 and 2).

\section{Clinical classification of high-risk patients}

We examined the clinical context of patients receiving the highest dose radiation. In accordance with previous studies, ${ }^{3}$ we classified patients with diagnosis of neoplasm as patients at high risk of receiving high doses of radiation. We reviewed the digital register to establish which patients, who underwent an imaging test, had the ICD11 code of neoplasms (from 1993, when the register started, until the date of the first imaging test they underwent in our study).

\section{Patient and public involvement}

Patients and the public were not involved in the design, conduct and reporting of the research.

\section{Statistical analysis}

We estimated the imaging test frequency as the number of people having at least one test during the study period until the 31 December 2018 (final exposure status) and it was classified by sex and age. We also estimated the per-patient cumulative diagnostic imaging test during the period of study by adding up the number of tests received by each patient, and then evaluated the differences by sex and age group using the $\mathrm{X}^{2}$ test. We also calculated the median and maximum number of imaging tests in our population and assessed the differences by sex and age using the Mann-Whitney U test.

Cumulative effective dose estimates were obtained by adding effective dose estimates received in each test in the patient's history. Data were expressed as the median, maximum and 25, 75, 95 percentiles. Differences by sex and age group were assessed using the Mann-Whitney $\mathrm{U}$ test.

We also classified the population according to the cumulative effective dose received during the period of study in the following way: $0-50 \mathrm{mSv},>50-100 \mathrm{mSv}$ and $>100 \mathrm{mSv}^{9}$ and evaluated the differences in these groups by sex and age group using the $\mathrm{X}^{2}$ test.

We carried out a subgroup analysis to analyse the different cumulative effective dose in patients having CT and in those having plain radiograph (online supplementary file 1$)$.

The statistical analyses of the data were performed with SPSS (V.25.0; SPSS). A p value of 0.05 was considered significant.

\section{RESULTS}

\section{Cohort characteristics}

The cohort included 232446 people: $53.7 \%$ women and $46.3 \%$ men. The distribution by sex and age was similar to Spanish general population.

Of 232446 people included in the cohort study, 154520 $(68.8 \%)$ underwent an imaging test associated with radiation during the period of study, with different frequency for men (69 265/107 622; 66.6\%) and women (85 $255 / 123196 ; 70.6 \%)(\mathrm{p}<0.001) \quad($ table 1$)$. The number of people having at least one examination during the study period (defined as imaging test frequency) ranged from $56.5 \%$ in the $20-30$ years age group to the highest percentage, $73.1 \%$, in the $60-80$ years group.

\section{Characteristics of imaging tests undergone during period of study}

Overall, the population had a total of 1335752 imaging tests during the period of study.

The type of imaging tests carried out were: 1110077 (83.0\%) plain radiography; 156848 (11.8\%) CT; 63157 $(4.8 \%)$ fluoroscopy and $5670(0.4 \%)$ interventional radiography. Men were more likely to have CT $(14.3 \%)$ than women $(10.1 \%)$ and women were more likely to have fluoroscopy $(7.1 \%)$ than men (1.6) $(\mathrm{p}=0.035)$. Moreover, the percentage of people who had a CT increased with age (from $1.2 \%$ in the $0-5$ years age group to $15.4 \%$ in the $60-70$ years age group (table 2 ). 

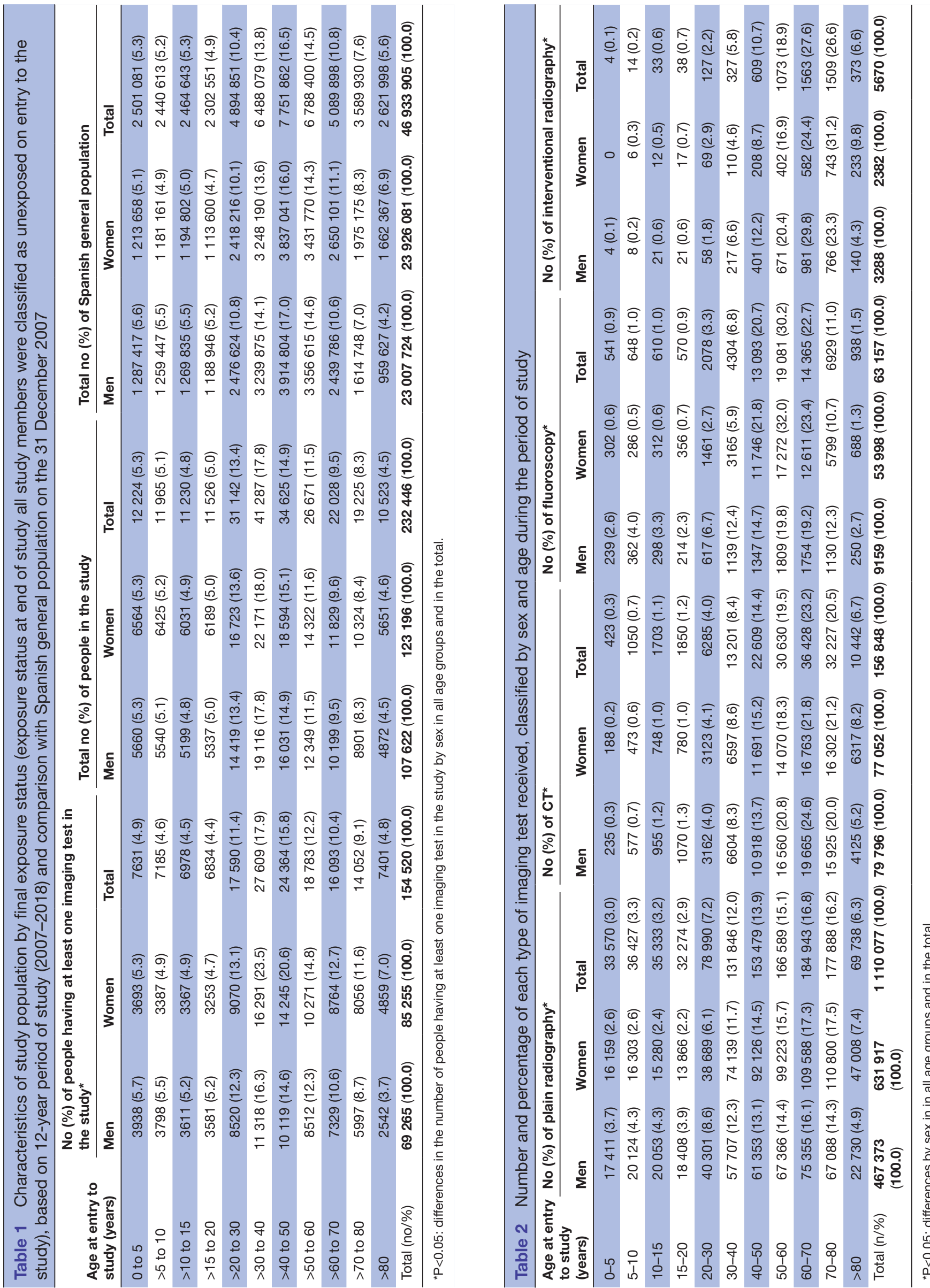


\section{Recurrent imaging tests}

The population exposed undergone a median of 5 imaging tests and $52.9 \%$ of the patients underwent five or more examinations. Women were more likely to have more cumulative imaging tests than men during this period (maximum 221 in men and 633 in women; IQR $2-10$ in men and $2-12$ in women, $\mathrm{p}<0.001)$.

Table 3 shows distribution data for per-patient imaging tests (median and maximum) by age and sex for each type of imaging test.

Moreover, $8.2 \%$ of the patients who had an imaging test during the period of study and 25.4\% (12 602/49 544) of the patients who had a CT, underwent five or more CTs $(5.5 \%(174 / 3187)$ in the $0-20$ years age group), with a maximum of 75 examinations; $1.8 \%$ of the patients who had an imaging test and 9.7\% (2849/29 314) of the patients who had a fluoroscopy examination, underwent five or more fluoroscopy examinations (1.9\% (28/1478) in the $0-20$ years age group), with a maximum of 18 examinations; $0.2 \%$ of the patients who had an imaging test and $5.8 \%$ of the patients who had an interventional radiography, underwent three or more interventional radiographies, with a maximum of 10 examinations, and $21.2 \%$ of the patients who had an imaging test and 21.6\% (32 778/151 980) of the patients who had a plain radiography, underwent 10 or more plain radiographies $(10.1 \%(2849 / 28356)$ in the $0-20$ years age group), with a maximum of 559 examinations.

Men were more likely to have more than five CTs than women $(27.8 \%$ vs $23.3 \%, \mathrm{p}<0.001)$, and less likely to have more than five fluoroscopy examinations $(2.3 \%$ vs $11.6 \%$, $\mathrm{p}<0.001)$ and more than 10 plain radiographies than women ( $19.6 \%$ vs $23.2 \%, \mathrm{p}<0.001$, respectively) (data not shown).

\section{Cumulative effective dose received during the period of study}

The median total cumulative effective dose including all imaging tests in all population exposed was $2.10 \mathrm{mSv}$ (maximum 3980.30). Women received more effective dose than men (median 2.38 vs median 1.90, $\mathrm{p}<0.001$ ). The cumulative effective dose increased with age: median 0.72 (maximum 47.15 ) in the $0-5$ years age group and median 10.20 (maximum 3980.309) in the $70-80$ years age group $(\mathrm{p}<0.001)$ (table 4$)$.

If we consider the cumulative effective dose associated with plain-radiograph (online supplementary table S3), the median total cumulative effective dose was $0.70 \mathrm{mSv}$ (maximum 2112.79). There were also differences by sex: women received more effective dose than men (median 1.02 vs median $0.64, \mathrm{p}<0.001$ ).

Considering the cumulative effective dose associated with CT (online supplementary table S4), the median total cumulative effective dose was $16.30 \mathrm{mSv}$ (maximum $1419.30)$. Men received more effective dose than women (median 19.80 vs median $13.20, \mathrm{p}<0.001$ ). $2.5 \%$ of the patients in the 0 to 20 group received more than $50 \mathrm{mSv}$.

A total of $4844(3.1 \%)$ people received cumulative doses between 50 and $100 \mathrm{mSv}$ and 2298 (1.5\%) people received doses greater than $100 \mathrm{mSv}$. Men were more likely to have cumulative effective dose above $50 \mathrm{mSv}$ (both between 50 and $100 \mathrm{mSv}(3.5 \%)$ and higher than $100 \mathrm{mSv}(1.8 \%)$, than women $(2.9 \%$ and $1.2 \%$, respectively) $(\mathrm{p}<0.001)$. Of the 2298 patients who received more than $100 \mathrm{mSv}$ during the 12-year study period, 725 $(33.3 \%)$ were patients in the $60-70$ years age group; 565 $(24.6 \%)$ were patients in the 50-60 years age group; 462 (20.1\%) were patients in the $70-80$ years age group and $350(15.2 \%)$ were patients in the $40-50$ years age group (table 5).

If we consider the cumulative effective dose associated with plain radiograph, almost $100 \%$ of people received cumulative effective dose below $50 \mathrm{mSv}$. Considering the cumulative effective dose associated with CT, $17.8 \%$ of people received doses above $50 \mathrm{mSv}(8.2 \%$ above 100 $\mathrm{mSv})$.

\section{Classification of high-risk patients}

Of the 154520 patients who had an imaging test during the period of study, $11072(7.1 \%)$ had a diagnosis of cancer during the period of study. Out of 2298 patients who received more than $100 \mathrm{mSv}, 1678(73.0 \%)$ had a diagnosis of cancer, compared with $43.14 \%$ of patients who received between 50 and $100 \mathrm{mSv}$ and $4.9 \%$ of patients who received less than $50 \mathrm{mSv}$.

\section{DISCUSSION}

This study provides an important information on the cumulative radiation dose received by patients in routine practice. We showed that the median cumulative effective dose including all the imaging tests during the 12-year study period was $2.10 \mathrm{mSv}$ (maximum 3980.30). However, the median cumulative effective dose associated with only CT was 16.30 (maximum 1419.30).

The median cumulative effective dose was, therefore, lower than the $100 \mathrm{mSv}$ threshold often considered for significant risks in stochastic theory. ${ }^{22}$ Nevertheless, 4844 (3.1\%) people received between 50 and $100 \mathrm{mSv}$ and $2298(1.5 \%)$ more than $100 \mathrm{mSv}$ during the study period. In addition, $17.8 \%$ of people who had CTs received doses above $50 \mathrm{mSv}$ and $8.2 \%$ of them, doses above $100 \mathrm{mSv}$. A previous study evaluated CT use in general practice during an 8-year period (1998-2005) and showed that nearly $50 \%$ of the population had CT and $1.2 \%$ of them received doses $>100 \mathrm{mSv}$. The longer follow-up period in our study (12 vs 8 years) does not justify the much higher cumulative effective dose associated with CT shown in our patients.

However, our frequencies are lower than those reported in a previous study where $15 \%$ received estimated cumulative effective doses of more than $100 \mathrm{mSv}^{3}{ }^{3}$ This study included adult patients who had received CT during the previous 22 years while our cohort study included general population. In addition, we only showed data from a 12-year period, so the percentage of patients with an effective dose higher than $100 \mathrm{mSv}$ during their lifetime 


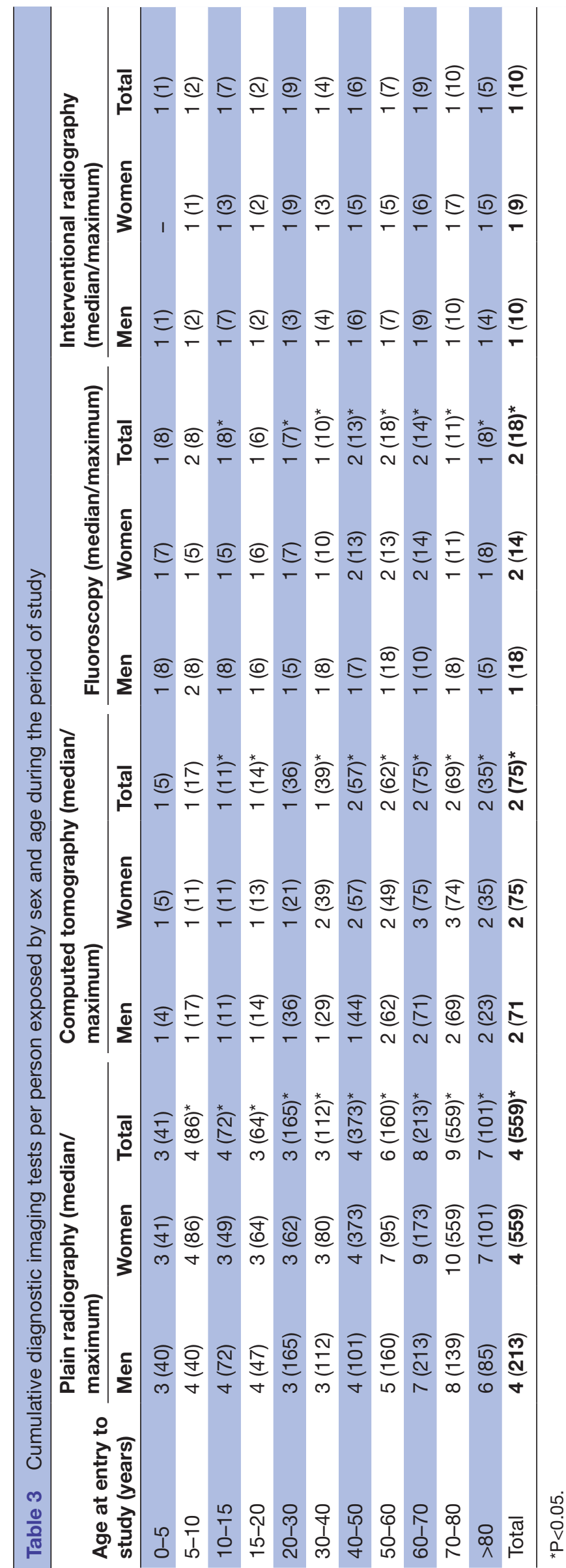




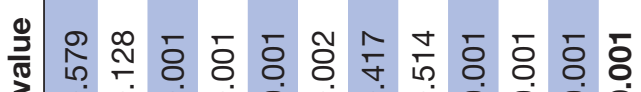

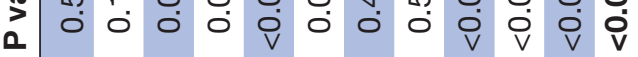

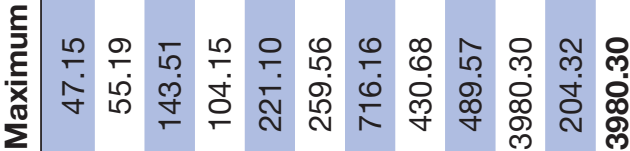
只

เి

ஊ ब U.

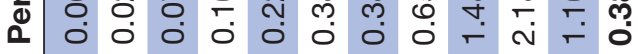

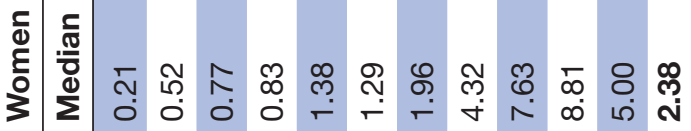

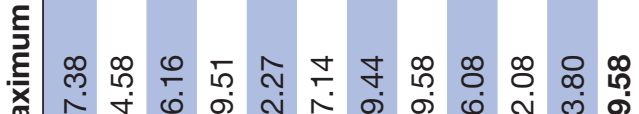
元 ले

온

ผ

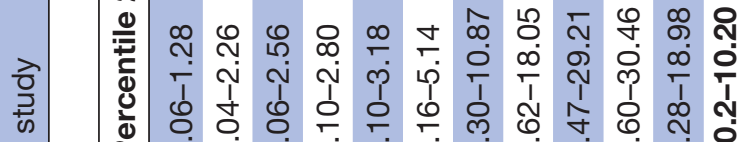
屯

음

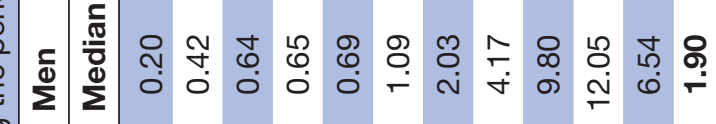

要

를

ర్d

要

ठ

कू

๘)

○ ब

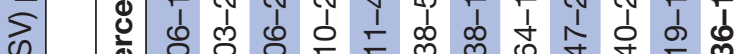

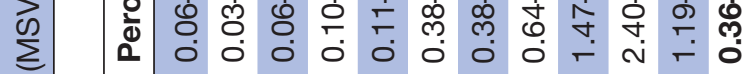

离

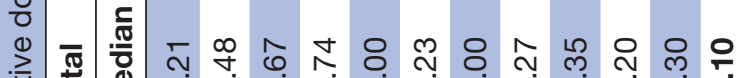

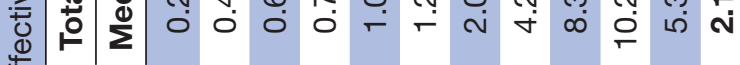

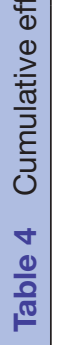

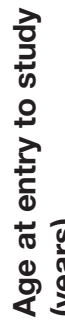

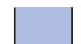

$\frac{2}{\frac{\pi}{2}}$

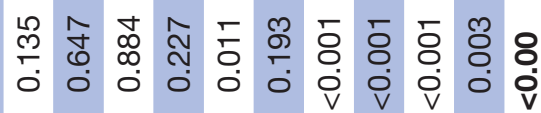

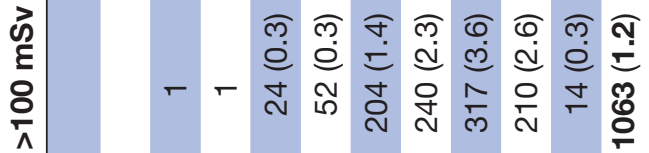

बำ ल ส

过

仓ัญ

b >

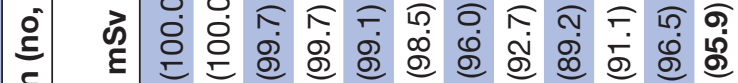

글

$\stackrel{5}{\Phi}$

ட.

ల్ల ల్ల ల్ల స్ల $\infty$

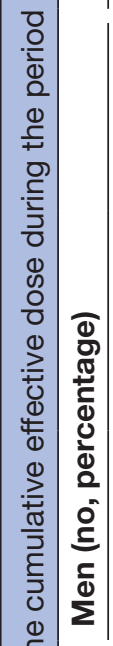

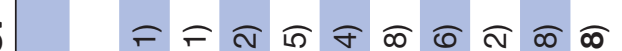

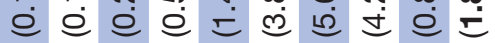

m 맘

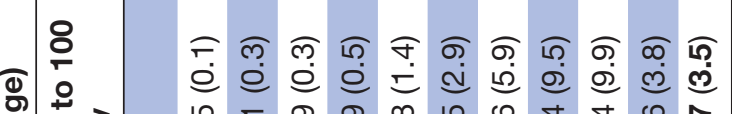

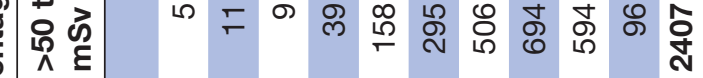

ว ด

ह

ㄴ.

ए।

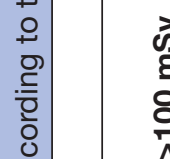

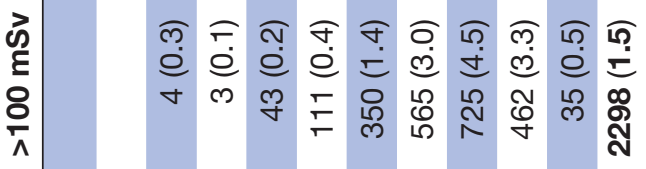

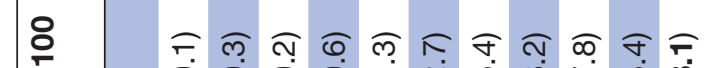

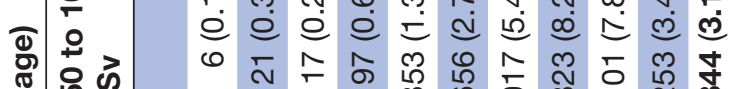
吾

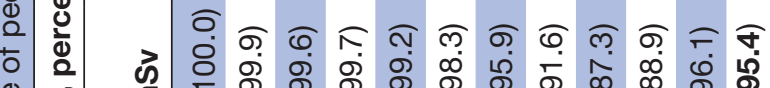

๑ $\quad$ ह

葛

음

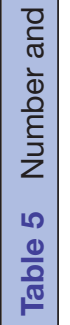

$\stackrel{m}{s}$

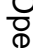

寻

음

क

象

$\vec{\circ}$

$\vec{\omega}$

응

$\stackrel{1}{7}$

ก

0

ठ

윽

$\vec{\infty}$

ゆ

응

옹

प

方

ำ

음

产

윽

긍

䒠

ํํํ

○

을

N

กิ

ত

밈

줄

$\stackrel{+}{\circ}$

?

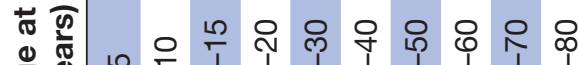

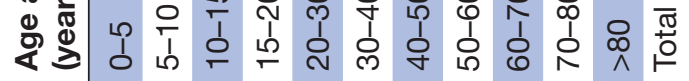


will be even higher. Moreover, according to linear theory, smaller doses have the potential to cause a small increase in cancer risk. ${ }^{6}$ However, the cancer rates did not change in our cohort during the period of study.

Previous research focused on patients $<20$ years of age ${ }^{23}$ showed that of the 22867 patients who had CT during an 8-year period, $1.6 \%$ received doses higher than 50 $\mathrm{mSv}$. In our cohort study, the percentage was lower, but we included all imaging tests (radiography and CT). In the subgroup analysis by type of imaging test, we observed higher rates in the CT group in the $0-20$ years age group $(2.5 \%)$. Greater efforts to decrease the number of recurrent CTs in children have to be implemented, taking into account that a recent study showed that even low doses of ionising radiation increase the risk of childhood leukaemia. $^{24}$

These results, which show high rates of population undergoing imaging tests, are in line with the DoseData Med II project, ${ }^{3}$ in which Spain had one of the greatest frequency of imaging tests per 1000 population in comparison with the European average.

We also found high rates of recurrent CT $25.4 \%$ of the patients who had a CT, underwent five or more CTs, with a maximum of 75 examinations). Previous studies have shown higher rates of recurrent CT (33\% of patients underwent five or more CT examinations), ${ }^{6}$ but they included a longer followed-up period (22 vs 12 years). Moreover, $5.8 \%$ of the patients who had an interventional radiography, underwent three or more interventional radiographies during the period of study, with a maximum of 10 examinations. Both interventional radiography and CT are associated with a relatively high dose of radiation. Plain radiography and fluoroscopy, although they are not associated with such high doses, also showed a high recurrent rate. Additional measures should be applied to control these recurrent rates, particularly to subgroups who are more prone to recurrent controls such as patients with chronic diseases like cancer.

In fact, as in previous studies, ${ }^{3}$ most of the patients who received more than $100 \mathrm{mSv}$ had previous history of malignancy. However, $27 \%$ of them had no underlying malignant disease. In both groups of patients, clinicians should balance the risk of the cumulative exposure against the benefit of recurrent imaging.

Most of our population younger than 20 years old received effective dose lower than $50 \mathrm{mSv}$ during the period of study; however, more than $40 \%$ of this population underwent five or more imaging tests during this period and $5 \%$ of them had five or more CTs. Moreover, the maximum number of plain radiography, CT, fluoroscopy and interventional radiography examinations undergone was $86,17,8$ and 7 , respectively, in this age group. The linear no-threshold model is very controversial and is considered of little relevance for doses below $100 \mathrm{mSv}$; nevertheless, we have to take into account that children are more sensitive to ionising radiation effects due to their high radiosensitivity. ${ }^{25}{ }^{26}$ In addition, previous studies have shown a possible risk of cancer from radiation associated with commonly used tests, such as CT scan, in children at very young ages. ${ }^{27}$

There is increasing international interest in reducing radiation doses from imaging tests. ${ }^{28}$ Previous studies have shown difficulties when implementing initiatives to reduce radiation exposure into clinical practice. For instance, communication with patients regarding associated risk is essential to get a rational use of diagnostic imaging test, but there is a lack of knowledge in the general population regarding radiation exposure and the associated risks related to these tests. ${ }^{29} 30$ In addition, recent studies showed that most clinicians were unaware of radiation exposure associated with imaging tests ${ }^{31-33}$ and that less than $50 \%$ of the imaging tests carried out in clinical practice were considered appropriate according to the available recommendations and $29.1 \%$ of the total collective effective dose was associated with inappropriate imaging tests. ${ }^{34}$

Assessing the amount of effective dose that patients receive during their lifetime, as the European Commission of Radiological Protection recommends, ${ }^{11}$ could, therefore, be considered a useful tool to raise awareness among clinicians and patients regarding the risks associated, and to help them to reach a shared decision when asking for imaging tests to reduce cancer risk. However, an effort should be made to reduce the great variation in CT protocols, technical parameters and radiation doses across countries. ${ }^{35}$

Limitations of our study included the retrospective design and lack of information regarding patients who might have been imaged outside the healthcare system, as well as radiation derived from nuclear medicine that also represents a relevant proportion of the collective population dose. ${ }^{12} 13$ However, as we stated previously, the publicly funded insurance scheme covers $98.5 \%$ of the Spanish population and only a small percentage of patients are likely to have had imaging tests outside this setting.

Moreover, given that we studied the imaging tests carried out during a 12-year period, some patients could have been lost to follow-up. Based on practice during this 12-year period, we estimated the proportion of imaging tests that would have been carried out during the remaining period if the patients had been in the cohort.

We used the available evidence to estimate the effective dose for each imaging test, as is proposed by the DoseData Med project. ${ }^{12}{ }^{13}$ However, this type of estimation has inherent limitations; it does not take into account the test date, the scanner model or the patient's characteristics. Nevertheless, it does not affect the overall result. It is also true that our results may differ from those of studies in different settings. We used effective dose to quantify the radiation exposure associated with each imaging test instead of organ doses. Absorbed organ doses are important for some procedures that either involve high doses or include sensitive tissues in the primary radiation beam. ${ }^{4}$ However, our aim was not to assess cancer risks associated with medical ionising radiation but to 
compare across the different imaging tests carried out in our population.

We included a general hospital and its catchment area (with a total population over 200000 people). Even though our results could have some limited generalisability in other settings, analysing this population provides important insights, showing as far as we know, the first evaluation of the cumulative effective dose in routine practice (including adults and children) according to age and sex over a 12-year period. In addition, as we showed in the result section, the population included in this study is similar to general Spanish population.

\section{CONCLUSIONS}

A total of $4844(3.1 \%)$ people received cumulative doses between 50 and $100 \mathrm{mSv}$ and 2298 (1.5\%) people received doses greater than $100 \mathrm{mSv}$ during the 12-year period of study. Considering only the doses associated with CT, $2.5 \%$ of the patients in the $0-20$ years age group received doses above $50 \mathrm{mSv}$. Moreover, the rate of recurrent examinations was high, especially in older patients, but also relevant in the $0-20$ years age group. These data could help clinicians to make an informed decision when asking for each imaging test, which would lead to lower cumulative lifetime radiation, and consequently a reduction in associated risks.

Contributors BLL, IG-A and JMS conceived of and designed the study. BLL and JMS acquired the data. BLL and JMS prepared the data and BLL, JMS and IG-A interpreted statistical analyses. BLL did the statistical analyses and drafted the data tables. BLL, JMS and IG-A cowrote the manuscript. All authors critically revised the paper for important intellectual content and approved the final version.

Funding The authors have not declared a specific grant for this research from any funding agency in the public, commercial or not-for-profit sectors.

Competing interests None declared.

Patient consent for publication Not required.

Ethics approval The study was approved by the institutional review board at San Juan Alicante Hospital (14/301).

Provenance and peer review Not commissioned; externally peer reviewed.

Data availability statement Data generated by the research that supports this manuscript will be available as soon as possible wherever legally and ethically possible.

Open access This is an open access article distributed in accordance with the Creative Commons Attribution Non Commercial (CC BY-NC 4.0) license, which permits others to distribute, remix, adapt, build upon this work non-commercially, and license their derivative works on different terms, provided the original work is properly cited, appropriate credit is given, any changes made indicated, and the use is non-commercial. See: http://creativecommons.org/licenses/by-nc/4.0/.

\section{REFERENCES}

1. Parkin DM, Darby SC. 12. cancers in 2010 attributable to ionising radiation exposure in the UK. Br J Cancer 2011;105(Suppl 2):S57-S65.

2. United Nations Scientific Committee on the Effects of Atomic Radiation (UNSCEAR), Effects of ionizing radiation. UNSCEAR 2006 report to the general assembly, with scientific annexes. United Nations, 2006.

3. Sodickson A, Baeyens PF, Andriole KP, et al. Recurrent CT, cumulative radiation exposure, and associated radiation-induced cancer risks from CT of adults. Radiology 2009;251:175-84.
4. Committee to Assess Health Risks from Exposure to Low levels of Ionizing Radiation; Nuclear and Radiation Studies Board, Division on Earth and Life Studies, National Research Council of the National Academies. Health risks from exposure to low levels of ionizing radiation: BEIR VII phase 2. Washington, DC: The National Academies Press, 2006.

5. National Research Council. Health risks from exposure to low levels of ionizing radiation: BEIR VII phase 2. Washington, DC: The National Academies Press, 2006.

6. Grant EJ, Brenner A, Sugiyama $\mathrm{H}$, et al. Solid cancer incidence among the life span study of atomic bomb survivors: 1958-2009. Radiat Res 2017:187:513-37.

7. Marant-Micallef $\mathrm{C}$, Shield KD, Vignat J, et al. The risk of cancer attributable to diagnostic medical radiation: estimation for France in 2015. Int J Cancer 2019;144:2954-63.

8. Bosch de Basea M, Moriña D, Figuerola J, et al. Subtle excess in lifetime cancer risk related to CT scanning in Spanish young people. Environ Int 2018;120:1-10.

9. Hall EJ, Brenner DJ. Cancer risks from diagnostic radiology. Br J Radiol 2008;81:362-78.

10. Pearce MS, Salotti JA, Little MP, et al. Radiation exposure from CT scans in childhood and subsequent risk of leukaemia and brain tumours: a retrospective cohort study. The Lancet 2012;380:499-505.

11. Council Directive 2013/59/Euratom of 5 December 2013 laying down basic safety standards for protection against the dangers arising from exposure to ionising radiation, and repealing directives 89/618/ Euratom, 90/641/Euratom, 96/29/Euratom, 97/43/Euratom and 2003/122/Euratom. OJ L 13 2014;57:1-73.

12. European Commission on Radiological Protection Publication 180 , 2014. Diagnostic reference levels in thirty-six European countries. Available: https://ec.europa.eu/energy/sites/ener/files/documents/ RP180.pdf

13. European Commission on Radiological Protection Publication 154, 2008. European guidance on estimating population doses from medical X-ray procedures. Available: http://ddmed.eu/_media/ background_of_ddm1:rp154.pdf

14. Guttikonda R, Herts BR, Dong F, et al. Estimated radiation exposure and cancer risk from CT and PET/CT scans in patients with lymphoma. Eur J Radiol 2014;83:1011-5.

15. Law M, Ma W-K, Chan E, et al. Evaluation of cumulative effective dose and cancer risk from repetitive full spine imaging using EOS system: impact to adolescent patients of different populations. Eur $J$ Radiol 2017;96:1-5.

16. AmisESJr, Butler PF, Applegate KE, et al. American College of radiology. American College of radiology white paper on radiation dose in medicine. J Am Coll Radiol 2007;4:272-84.

17. Spanish statistical office: population figures and demographic Censuses. Available: https://www.ine.es/dynt3/inebase/en/index. $\mathrm{htm}$ ?padre $=1894 \&$ capsel $=1895$

18. Vilar-Palop J, Vilar J, Hernández-Aguado I, et al. Updated effective doses in radiology. J Radiol Prot 2016;36:975-90.

19. Shrimpton PC, Hillier MC, Lewis MA, et al. National survey of doses from CT in the UK: 2003. Br J Radiol 2006;79:968-80.

20. Mettler FA, Huda W, Yoshizumi TT, et al. Effective doses in radiology and diagnostic nuclear medicine: a catalog. Radiology 2008;248:254-63.

21. Cohnen M, Poll LJW, Puettmann C, et al. Effective doses in standard protocols for multi-slice CT scanning. Eur Radiol 2003;13:1148-53.

22. Lin EC. Radiation risk from medical imaging. Mayo Clin Proc 2010;85:1142-6.

23. Inman M, Otley A, Dummer T, et al. Childhood exposure to ionizing radiation from computed tomography imaging in nova Scotia. Paediatr Child Health 2015;20:381-5.

24. Nikkilä A, Raitanen J, Lohi O, et al. Radiation exposure from computerized tomography and risk of childhood leukemia: Finnish register-based case-control study of childhood leukemia (FRECCLE). Haematologica 2018;103:1873-80.

25. Mathews JD, Forsythe AV, Brady Z, et al. Cancer risk in 680000 people exposed to computed tomography scans in childhood or adolescence: data linkage study of 11 million Australians. BMJ 2013;346:f2360-2360.

26. Meulepas JM, Ronckers CM, Smets AMJB, et al. Radiation exposure from pediatric $\mathrm{CT}$ scans and subsequent cancer risk in the Netherlands. J Natl Cancer Inst 2019;111:256-63.

27. Rajaraman P, Simpson J, Neta G. Et al. early life exposure to diagnostic radiation and ultrasound scans and risk of childhood cancer: case-control study. BMJ 2011:342-472.

28. Amis ES, Butler PF. ACR white paper on radiation dose in medicine: three years later. J Am Coll Radiol 2010;7:865-70. 
29. Lumbreras B, Vilar J, González-Álvarez I, et al. Avoiding fears and promoting shared decision-making: how should physicians inform patients about radiation exposure from imaging tests? PLoS One 2017; 12:e0180592.

30. Bedetti G, Pizzi C, Gavaruzzi G, et al. Suboptimal awareness of radiologic dose among patients undergoing cardiac stress scintigraphy. J Am Coll Radiol 2008;5:126-31.

31. Lumbreras B, Vilar J, González-Álvarez I, et al. Evaluation of clinicians' knowledge and practices regarding medical radiological exposure: findings from a mixed-methods investigation (survey and qualitative study). BMJ Open 2016;6:e012361.
32. Soye JA, Paterson A. A survey of awareness of radiation dose among health professionals in Northern Ireland. Br J Radiol 2008;81:725-9.

33. Zhou GZ, Wong DD, Nguyen LK, et al. Student and intern awareness of ionising radiation exposure from common diagnostic imaging procedures. J Med Imaging Radiat Oncol 2010;54:17-23.

34. Vilar-Palop J, Hernandez-Aguado I, Pastor-Valero M, et al. Appropriate use of medical imaging in two Spanish public hospitals: a cross-sectional analysis. BMJ Open 2018;8:e019535.

35. Smith-Bindman R, Wang $Y$, Chu $P$, et al. International variation in radiation dose for computed tomography examinations: prospective cohort study. BMJ 2019;169. 